\title{
Status and structure of the griffon vulture (Gyps fulvus) population in Crete
}

\section{Eur J. Wildl Res (2005) 51: 223-231}

Several mistakes occurred in this paper:

1. In Table 3 an author's name was misspelled twice in the Reference section. The correct Table appears below.

2. The captions for Figs. 3 and 4 were mixed up. The correct captions appear below.
Fig. 3 Population trends of the griffon vulture in Crete during 1996-2002

Fig. 4 Distribution of colony size of griffon vultures (i.e., number of colonies, breeding and laying pairs) in Crete during 1996-2002

3. Figure 3 was incomplete. The correct Fig. 3 is repeated below.

Table 3 Age classes (\%) in populations of large raptors

\begin{tabular}{lllll}
\hline Species & Adults & Immature & Region & Reference \\
\hline Haliaeetus vocifer & 76 & 24 & West Africa & Brown and Cade 1972 \\
Terathopius ecaudatus & 64 & 36 & South Africa & Brown and Cade 1972 \\
Terathopius ecaudatus $^{\text {Aquila chrysaetos }}{ }^{\mathrm{a}}$ & 69 & 31 & West Africa & Brown and Cade 1972 \\
Aquila aldaberti $^{\mathrm{a}}$ & 87.5 & 12.5 & Scotland & Watson 1997 \\
Gypaetus barbatus $^{\text {Gypaetus barbatus }}$ & 86 & 14 & Spain & Ferrer 2001 \\
Gypaetus barbatus & 77.4 & 22.6 & Ethiopia & Brown 1977 \\
Gyps coprotheres & 63 & 37 & South Africa & Brown 1997 \\
Gyps fulvus & 50 & 50 & Spain & Antor 1999 \\
\hline
\end{tabular}

${ }^{\mathrm{a}}$ Increased human-induced mortality of immature birds

${ }^{\mathrm{b}}$ Population supported by supplementary feeding

The online version of the original article can be found at: http://dx.doi.org./10.1007/s10344-005-0101-4

S. M. Xirouchakis $(\bowtie) \cdot$ M. Mylonas

Biology Department, Natural History Museum of Crete,

University of Crete,

P.O. Box 2208, 71409 Heraklion, Crete, Greece

e-mail: sxirouch@nhmc.uoc.gr 


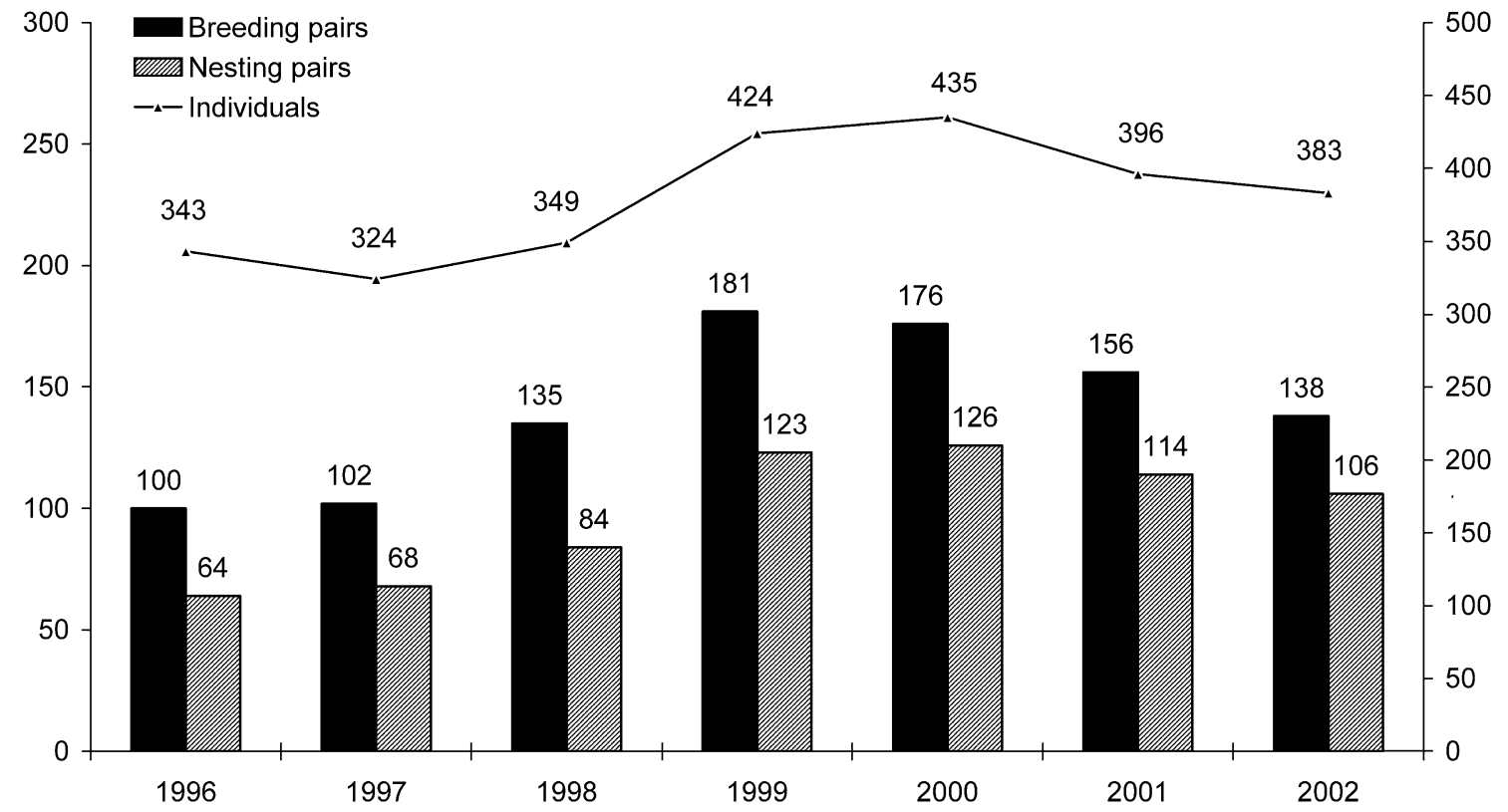

Fig. 3 Population trends of the griffon vulture in Crete during 1996-2002 